\title{
Identifying predictors associated with the severity of eating concerns in females with eating disorders
}

\author{
Stefania Cella, Annarosa Cipriano, Mara Iannaccone, Paolo Cotrufo \\ Observatory on Eating Disorders, Department of Psychology, University of Campania Luigi Vanvitelli, Caserta, Italy
}

\begin{abstract}
Considering how to improve efficacy of therapeutic strategies, the overall objective of the present study was to investigate the extent of eating concerns and to identify predictors associated with the severity of disordered eating symptomatology among people with eating pathologies. We screened 80 female eating disordered patients, ranging from 13 to 40 years, by means of self-report measures of parental behavior as perceived by the offspring, self-esteem, perfectionism, body shame and eating disorder severity. Self-reported weight and height were obtained. The diagnosis of bulimia nervosa resulted to be associated with a greater severity of the eating symptomatology. Maladaptive perfectionism, body shame and self-esteem, significantly predicted the level of eating concerns. The recognition of potential maintaining factors may support the choice of particular therapeutic strategies to improve the treatment of eating pathologies and their outcomes.
\end{abstract}

Key words: Eating disorders; Parental bonding; Self-esteem; Perfectionism; Body shame.

\section{Introduction}

Eating disorders show a chronic course and result in significant functional impairment, emotional distress, and medical problems (Hudson, Hiripi, Nope \& Kessler,

Correspondence: Paolo Cotrufo, Observatory on Eating Disorders, Department of Psychology, University of Campania Luigi Vanvitelli, viale Ellittico 31, 81100 Caserta, Italy.

Tel: +39.0823.274773 - Fax: +39.0823 .274773$

E-mail: paolo.cotrufo@unicampania.it

Contributions: the authors contributed equally.

Conflict of interest: the authors declare no potential conflict of interest.

Acknowledgements: the authors would like to thank Dr. Laura Dalla Ragione, Dr. Concetta De Salvo and Dr. Sabato Antonio Manzi for their help with data collection.

Citation: Cella, S., Cipriano, A., Iannaccone, M., \& Cotrufo, P. (2017). Identifying predictors associated with the severity of eating concerns in females and eating disorders. Research in Psychotherapy: Psychopathology, Process and Outcome, 20(1), 91-99. doi: 10.4081/ripppo.2017.199

Received for publication: 24 September 2016.

Revision received: 8 November 2016.

Accepted for publication: 9 December 2016.

This work is licensed under a Creative Commons Attribution NonCommercial 4.0 License (CC BY-NC 4.0).

CCopyright S. Cella et al., 2017

Licensee PAGEPress, Italy

Research in Psychotherapy:

Psychopathology, Process and Outcome 2017; 20:91-99

doi:10.4081/ripppo.2017.199
2007). An epidemiological study suggested that approximately $7.5 \%$ of young women meet criteria for a DSMIV-TR 4 (APA, 2000) eating disorder of anorexia nervosa (AN), bulimia nervosa (BN), or binge eating disorder (BED) (Hudson, Hiripi, Pope, \& Kessler, 2007). So it is important to identify factors that contribute to the development and maintenance of eating disorders, in order to implement the more functional therapeutic approach.

In this framework there has been interest in investigating the etiology as well as predictors of eating psychopathology (e.g., Calam \& Waller, 1998; Grant \& Fodor, 1986; Greenberg \& Harvey, 1986; Wood, Waller, \& Gowers, 1994). Various factors have been hypothesized as having an effect on the development, course and maintenance of ED. Sociocultural factors, dieting, self-esteem, body image, social support, social adjustment, coping, attitudes about food and eating, body dissatisfaction, family interaction and environment, body concern, major negative life events, and a childhood history of being teased for one's appearance are among the factors that have been investigated separately or in various combinations (Ghaderi, 2001).

Investigating factors that contribute to the development of eating disorders (EDs) has been the focus of diverse previous studies (e.g., Teixeira, Pereira, Marques, Saraiva, \& de Macedo 2016; De Panfilis, Rabbaglio, Rossi, Zita, \& Maggini, 2003; Ghaderi, 2001). In terms of the ED maintenance, several variables have been suggested as possible perpetuating factors for these pathologies and have been detected as obstacle for psychotherapy process to heal (Bardone-Cone et al., 2007).

Empirical evidence suggests that family factors are important features in the etiology of both eating disorders and disordered eating behaviors and attitudes (e.g., Polivy \& Herman, 2002; Horesh, Sommerfeld, Wolf, Zubery, \& 
Zalsman, 2015). Selvini Palazzoli (1963) observed specific disturbances in early child-mother relationship and some typical patterns in families with anorexic offspring, such as maternal intrusiveness and over-involvement. Similarly, Minuchin et al. (1975) have described family characteristics of enmeshment, overprotective, rigidity, and lack of conflict resolution. A body of research has focused on perceived parental bonding, [generally assessed by the Parental Bonding Instrument (Parker, Tupling, \& Brown, 1979)] as risk factors in the development of eating disorder-related symptoms, concerns and behaviors (Tetley, Moghaddam, Dawson, \& Rennoldson, 2014). Particularly, a parenting style based on low care-high control has been shown to predict body image disturbance in female ED outpatients (De Panfilis, Rabbaglio, Rossi, Zita, \& Maggini, 2003) and to be the most frequent type amongst ED patients (Jáuregui Lobera, Bolaños Ríos, \& Garrido Casals, 2011). High levels of maternal intrusiveness and overprotectiveness (Laporte, Marcoux, \& Guttman, 2001; Swanson et al., 2010) and low levels of parental care have been shown to be associated with anorexic symptomatology (Fassino, Amianto, Rocca, \& Daga, 2010). Bulimic women reported low levels of parental warmth, affection, empathy (Fassino, Amianto, Rocca, \& Daga, 2010) and relatively high levels of paternal overprotection (Calam, Waller, Slade, \& Newton, 1990). Among ED patients, high overprotection has been associated with suicidal behavior(Yamaguchi et al., 2000). In the study by Canetti, Kanyas, Lerer, Latzer, \& Bachar (2008), maternal control and paternal care were associated with higher symptom severity among anorexic women. Comparing women diagnosed with ED to healthy controls and a psychiatric patients group (diagnosed with anxiety or depressive disorders), negative perception of the father's parenting style and a low quality of relationship have been found relevant to understand the ED onset and maintenance (Horesh, Sommerfeld, Wolf, Zubery, \& Zalsman, 2015). Similarly, paternal (but not maternal) criticism predicted less psychological improvement in eating disorder psychopathology at the end of treatment (Rienecke, Accurso, Lock, \& Le Grange, 2016). Overall, eating disorders might affect, in turn, the family relationships and home environment in a way that allow symptom maintenance (Loeb, Lock, Le Grange, \& Greif, 2012).

Moreover, researchers (Perry, Silvera, Neilands, Rosenvinge, \& Hanssen, 2008; Cella, Iannaccone, \& Cotrufo, 2014) have begun to consider the existence of possible mediating factors between parental bonding and eating pathologies: specifically, parental bonding has a relevant impact factor on offspring's self-concept and low self-esteem that, in turn, affects ED vulnerability. The experience of shame (Murray, Waller, \& Legg, 2000) and the development of unhealthy core beliefs (Meyer \& Gillings, 2004) appear to be important in determining the effect that perceived parental style has on bulimic psychopathology in a non-clinical group of women.

On the other hand, other studies approached this issue in terms of the attachment theory, and have highlighted the prevalence of insecure attachment patterns in ED patients (Armstrong \& Roth, 1989; Brown \& Wright, 2001). A number of studies have shown that an impoverished sense of self is an important contributor to ED symptomatology (Courtney, Gamboz, \& Johnson, 2008; Stein \& Corte, 2007; Polivy \& Herman, 2002) and it is correlated with a negative outcome (La Mela, Maglietta, Lucarelli, Mori, \& Sassaroli, 2013). Nevertheless, some studies (e.g., Young, Clopton, \& Bleckley, 2004) do not support the existence of a direct relationship between low self-esteem and eating disturbance. In a study carried out by Young et al. (2004), self-esteem did not emerge as a significant predictor of bulimic behavior in college women, and ineffectiveness seems to be not a specific characteristic of eating disorder patients but, more in general, of clinical groups (Jacobi, Paul, De Zwaan, Nutzinger, \& Dahme, 2004). In a more recent research, self-esteem has$n$ 't been found to be the primary predictor of disordered eating (Shea \& Pritchard, 2007). In the field of eating disorders, this great dis-homogeneity of literature on the concept of self-esteem may be related to the sampling procedures and methodological shortcomings.

Several studies have associated eating disorder patterns, low self-esteem and perfectionism in many ways (Fairburn, 1995; Wade, Wilksch, Paxton, Byrne, \& Austin, 2015). Perfectionism predicts ED onset and maintaining (Holland, Bodell, \& Keel, 2013). Individuals with high levels of perfectionism might be at risk for a long disease duration and a poor prognoses (Egan, Wade, \& Shafran, 2011; Nilsson, Sundbom, \& Hägglöf, 2008; Sutandar-Pinnock, Blake Woodside, Carter, Olmsted, \& Kaplan, 2012; Bizeul, Sadowsky, \& Rigaud, 2001). Nevertheless, some studies have not found a direct relationship between perfectionism and eating problems (Joyce, Watson, Egan, \& Kane, 2012) and, as previously suggested (Watson, Steele, Bergin, Fursland, \& Wade, 2011), the role of perfectionism in the etiology and maintenance of EDs remains elusive. Some studies seem to suffer serious methodological limitations; multivariate model may be particularly pertinent to understand the effect of perfectionism on the development of eating disorders (Bardone-Cone et al., 2007). For example, Bardone et al. (2000) highlight an interactive model implicating high perfectionism, low self-esteem, and body dissatisfaction in the onset and maintenance of bulimic symptoms. Contrary to their hypotheses, La Mela and colleagues (2015) did not find confirmation that the relationship between weight and shape concerns, and binge episodes was mediated by any dimensions of perfectionism and moderated by low levels of self-esteem. The validity of the interactive model remains controversial, and may be limited by an inadequate conceptualization of the perfectionism construct.

The severity of eating disorder symptomatology has been also associated to shame about the body and in eat- 
ing context (Burney \& Irwin, 2000). Negative body image, particularly in relation to shame and concern with public appearance, was found to have the strongest relationship to binge eating status (Cargill, Clark, Pera, Niaura, \& Abrams, 1999). Bodily shame was the strongest ED risk predictor among normal weight controls too. However, gender, BMI and maternal care were also detected to predict eating pathology risk among this population. One study (Hayaki, Friedman, \& Brownell, 2001) found that women with bulimia nervosa (based on elevated scores on a self-report measure), recruited from an eating disorders clinic, reported more shame than those who had subthreshold levels of bulimic symptoms. The relationship between obesity and shame has also been demonstrated (Sjöberg, Nilsson, \& Leppert, 2005). Although body shame has been found to be a strong predictor of disordered eating (Jankauskiene \& Pajaujiene, 2012; Doran \& Lewis, 2012; Troop \& Redshaw, 2012), few studies have investigated the role of this factor in ED development and persistence.

Up till now, studies specifically evaluating a number of predictors associated with the severity of eating symptoms are contradictory in the literature, and few studies have tested for interactions among risk factors (Kraemer, Stice, Kazdin, Offord, \& Kupfer, 2001; Stice, Marti, \& Durant, 2011; Hilbert, Pike, Goldschmidt, Wilfley, Fairburn, Dohm, 2014).

This research attempted to answer an important question: which of the individual variables significantly predicts the level of eating concerns for ED patients? Our theoretical model implicates the confluence of high levels of parental intrusiveness and perfectionism, sense of ineffectiveness and experience of shame as being critical to the development of eating disorders.

Considering how to improve efficacy of therapeutic strategies, the overall objective of the present study was to investigate the extent of eating concerns and to identify predictors associated with the severity of disordered eating symptomatology among women who were diagnosed with eating disorders.

Our general assumption was that ED patients share similar psychological characteristics, suggesting possible shared pathways between the different diagnostic categories for eating disturbances (Cotrufo, Gnisci, \& Caputo, 2005).

\section{Materials and Methods}

Our study has been approved by the Ethic Board of the Department of Psychology and by the Ethic Committee of the Second University of Naples.

\section{Participants}

One hundred female inpatients were recruited from specialized residential ED treatment units in Northern,
Central and Southern Italy. All participants had a primary Diagnostic and Statistical Manual fourth edition (DSMIV)(APA, 1994) eating disorder diagnosis. Diagnosis was assigned at intake by ED clinicians who conducted a clinical interview. Participants were tested at variables points in treatment, but constantly in early stages, at which point strong treatments effects were improbable. We excluded 20 questionnaires because of non-completion, so the final sample consisted of 80 female.

\section{Measures}

Each patient self-reported the current weight $(\mathrm{kg})$ and height $(\mathrm{m})$ and completed the following questionnaires.

\section{Socio-demographic data and personal background schedule}

Participants were asked to fill in a socio-demographic schedule, including gender, age at the time of assessment, ED duration and socio-economic background.

\section{The Parental Bonding Instrument}

The Parental Bonding Instrument (PBI; Parker, Tupling, \& Brown, 1979), a 50-item self-report questionnaire, was used to measure parental behavior as perceived by the offspring. The tool investigates two principal areas of parental behaviors and attitudes: parental care (behaviors indicating affection and warmth or coldness and rejection) and parental overprotection (behaviors indicating encouragement of autonomy/independence as opposed to strict control with regulations and intrusiveness). Participants were asked to rate how much they agreed with various statements (e.g. Spoke to me in a warm and friendly voice, Appeared to understand my problems and worries, Let me do those things I liked doing). Response options for items range from 3 (very like) to 0 (very unlike); however, not all items are scored in the same direction. The PBI was asked separately for each participant's mother and father. Sample Cronbach's alpha ranges from .88 to .92 .

\section{The Rosenberg Self Esteem Scale}

The Rosenberg Self Esteem Scale (RSES; Rosenberg, 1965) is a 10-item self-report measure assessing the global self-esteem. A sample item from the RSES is I feel I do not have much to be proud of. Participants answered each item using a 4-point Likert scale from 0 (Strongly agree) to 3 (Strongly disagree). Scores range from 0 to 30 , with lower scores indicating lower self-esteem. Sample Cronbach's alpha $=.88$.

\section{The Experience of Shame Scale}

The Experience of Shame Scale (ESS; Andrews, Qian, \& Valentine, 2002) is a 25-item questionnaire to assess the frequency of shame experiences over the past year related to one's character (e.g. Have you felt ashamed of any of your personal habits?), behavior (e.g. 
Have you felt ashamed when you said something stupid?) and body (e.g. Have you wanted to hide or dissimulate your body or any part of it?). Participants answered each item using a 4-point Likert scale from 1 (Not at all) to 4 (Very much). However, in the current study, only Bodily Shame subscale was relevant to hypothesis. Sample Cronbach's alpha=.79.

\section{The Multidimensional Perfectionism Scale}

The Multidimensional Perfectionism Scale (MPS; Frost, Marten, Lahart, \& Rosenblate, 1990) was used to assess several dimensions of perfectionism: doubts about the individual's own actions, personal standards, organization, excessive concern with mistakes, parental expectations and parental criticism. Participants had to rate how much they agreed with 35 statements using a five point Likert scale from Strongly agree to Strongly disagree (e.g. Organization is very important to me, If I fail partly, it is as bad as being a complete failure). Because of its weak correlation with the other subscales, some research concludes that Organization reflects adaptive perfectionism while Concern over Mistakes, Doubt about Action, Parental Expectations, Parental Criticism and Personal Standards reflect maladaptive perfectionism (Frost, Marten, Lahart, \& Rosenblate, 1990). Sample Cronbach's alpha ranges from .68 to .90 .

\section{Eating Disorder Risk Composite Scale}

Eating Disorder Risk Composite (EDRC) Scale from the Eating Disorders Inventory-3 (EDI-3; Garner, 2004) was administered. The EDRC can be used for screening purposes or to obtain one score reflecting the level of eating concerns (Garner, 2004). Participants were asked to rate how much they agreed with 25 statements (e.g. I eat sweets and carbohydrates without feeling nervous, I feel extremely guilty after overeating) with answers ranging over a Likert scale from 0 (always) to 4 (never). Sample Cronbach's alpha $=.92$. Moreover, the participants filled out the Eating Disorder Symptom Checklist-3 (Garner, 2004) a behavioral checklist to assess symptom frequency (e.g. binge eating, self-induced vomiting, use of laxatives, diet pills, diuretics).

\section{Procedure}

After obtaining the consent of the participants and their parents or legal caregivers, it was explained that participation in the study was completely voluntary and all individuals were informed that responses would be completely confidential. All of them agreed to participate. As a part of routine clinical practice, patients compiled the self-report measures in a printed version, which took approximately 30-45 minutes to finish. Participants were encouraged to fill out the questionnaires in private and as accurately as possible and were debriefed upon conclusion of their questionnaires.

\section{Data analysis}

SPSS was used for all analyses and a significance level of $\mathrm{P}<.05$ was selected. First, comparisons between diagnostic groups were made using Kruskal-Wallis tests to investigate differences between patients with different diagnosis in terms of the study variables. Post-hoc analyses were performed by employing the Mann-Whitney U Tests with a Bonferroni correction $(.05 / 3=.0167)$. Next, Pearson correlation coefficients were computed to investigate associations among all of the study variables. Finally, the assumptions of multiple regression were satisfied (i.e. distribution, collinearity). Therefore, the contribution of parental characteristics, self-esteem, shame and perfectionism in predicting ED risk was assessed through a stepwise linear regression analyses performed on EDRC score. For regression equations using six or more predictors, an absolute minimum of 10 participants per predictor variable is appropriate (VanVoorhis \& Morgan, 2001).

\section{Results}

\section{Description of the sample}

All cases were Caucasian females $(\mathrm{N}=80)$. Ages ranged from 13 to 40 with a mean age of 25.35 $(\mathrm{SD}=7.68)$. The diagnostic categories represented by the sample comprised $48.8 \%(\mathrm{~N}=39)$ anorexia nervosa, $36.3 \%(\mathrm{~N}=29)$ bulimia nervosa, and $15 \%(\mathrm{~N}=12)$ binge eating disorder. Table 1 describes the socio-demographic information and the personal background across diagnostic subtypes. Most participants ( $\mathrm{N}=44,55 \%)$ fell into the low to middle socio-economic category. Fifty-nine patients $(73.8 \%)$ had married/cohabiting parents, $9(11.3 \%)$ had divorced parents, $2(2.5 \%)$ came from a family in which both parents were dead, $8(10 \%)$ came from a family in which the father was dead and $1(1.3 \%)$ came from a family in which the mother was dead.

\section{Data screening and descriptive statistics}

A summary of the means, standard deviations and bivariate correlations for all of the study variables are reported in Table 2 .

\section{Group comparisons of study variables}

Age was similar between the three groups. There were no differences among the diagnostic groups on any of the study variables, i.e. ESS Bodily Shame, PBI Parental Care, PBI Parental Protectiveness, MPS Maladaptive Perfectionism, MPS Organization, RSES Self-esteem, except for the EDI-3 EDRC score and, as expected, for the BMI (Table 3). Bulimic patients scored higher on EDRC score and BED patients scored higher on BMI compared to the others.

\section{Predictors of the level of eating concerns}

As displayed in Table 4, regression analyses indicated that maladaptive perfectionism $(\mathrm{P}<.001)$, body shame 
$(\mathrm{P}<.05)$ and self-esteem $(\mathrm{P}<.05)$, significantly predicted ED symptom severity. Adaptive perfectionism, parental care and protectiveness did not predict the level of eating concerns. Maladaptive perfectionism was more closely linked with level of eating symptomatology followed by body shame and low self-esteem. The total variability of the dependent variable explained by the model was $45 \%$ (adjusted $R^{2}=.450$ ).

\section{Discussion}

Within the framework of the research in psychotherapy and considering how to detect psychological features which could improve efficacy of specific therapeutic goals, the main aim of the current study was to investigate the extent of eating concerns and their association with perceived parental bonding, self-esteem, perfectionism and body shame among eating disordered individuals.

Of particular interest are the results of the comparisons between $\mathrm{AN}, \mathrm{BN}$ and $\mathrm{BED}$ patients on the study variables that found only a few statistically significant differences. Our findings suggest that patients who fall below the different diagnostic categories for eating disturbances share similar psychological characteristics. However, it is interesting to note that the diagnosis of Bulimia Nervosa could be associated with a greater severity of the eating symptomatology. In our opinion, these results seem to confirm the hypothesis that different types of EDs could have the same psychopathological core and Bulimia could be considered as a failed anorexia (Cotrufo, Gnisci, \& Caputo, 2005). Bulimic subjects feel they have lost their iron willpower and they have melted away like snow in the sun (Cotrufo, 2005). Future treatment research should be broadened to investigate this question.

Most worth mentioning in this analysis was the positive and significant prediction of the eating concerns by maladaptive (but not adaptive) perfectionism. This finding is in line with the view that only maladaptive perfectionism

Table 1. Socio-demographic characteristics and personal background of anorexia nervosa, bulimia nervosa and binge eating disorder patients $(\mathrm{N}=\mathbf{8 0})$.

\begin{tabular}{|c|c|c|c|c|}
\hline \multirow{2}{*}{\multicolumn{2}{|c|}{ Variables }} & \multicolumn{3}{|c|}{ Average scores } \\
\hline & & $\begin{array}{c}\text { AN } \\
(\mathbf{N}=39)\end{array}$ & $\begin{array}{c}\mathrm{BN} \\
(\mathrm{N}=\mathbf{2 9})\end{array}$ & $\begin{array}{c}\text { BED } \\
(\mathrm{N}=12)\end{array}$ \\
\hline Age & & $24.74 \pm 8.24$ & $25.03 \pm 6.22$ & $28.08 \pm 9.02$ \\
\hline Body mass index $\left(\mathrm{kg} / \mathrm{m}^{2}\right)$ & & $17.94 \pm 3.01$ & $20.24 \pm 5.17$ & $27.52 \pm 7.80$ \\
\hline Eating disorder duration (years) & & $9 \pm 6.88$ & $9.90 \pm 6.05$ & $8.92 \pm 8.39$ \\
\hline Socio-economic background, n (\%) & $\begin{array}{l}\text { Low } \\
\text { High }\end{array}$ & $\begin{array}{l}20(51.3) \\
19(48.7)\end{array}$ & $\begin{array}{l}16(55.2) \\
13(44.8)\end{array}$ & $\begin{array}{l}8(66.7) \\
4(33.3)\end{array}$ \\
\hline
\end{tabular}

AN, anorexia nervosa; BN, bulimia nervosa; BED, binge eating disorder.

Table 2. Means, standard deviations and correlations of the study variables in the complete sample (N=80).

\begin{tabular}{|c|c|c|c|c|c|c|c|}
\hline & 1 & 2 & 3 & 4 & 5 & 6 & 7 \\
\hline 1 & - & & & & & & \\
\hline 2 & $-.36 * *$ & - & & & & & \\
\hline 3 & .05 & .11 & - & & & & \\
\hline 4 & -.19 & $.36^{* *}$ & $-.37 * *$ & - & & & \\
\hline 5 & .12 & .02 & -.10 & $.44 * *$ & - & & \\
\hline 6 & -.06 & .11 & $-.31 * *$ & $.31 * *$ & .04 & - & \\
\hline 7 & -.09 & .17 & $-.51 * *$ & $.54 * *$ & $.23 *$ & $.48 * *$ & - \\
\hline Mean & 36.82 & 32.70 & 12.05 & 88.66 & 23.12 & 13.29 & 59.12 \\
\hline SD & 14.06 & 14.75 & 5.74 & 19.26 & 5.73 & 2.95 & 21.99 \\
\hline
\end{tabular}

1, PBI parental care; PBI, Parental Bonding Instrument; 2, PBI parental protectiveness; 3, RSES self-esteem; RSES, Rosenberg Self Esteem Scale; 4, MPS maladaptive perfectionism; MPS, Multidimensional Perfectionism Scale; 5, MPS organization; 6, ESS bodily shame; ESS, Experience of Shame Scale; 7, EDI-3 EDRC, Eating Disorder Risk Composite from the Eating Disorders Inventory-3; SD, standard deviation. ${ }^{*} \mathrm{P}<.01 ;{ }^{*} \mathrm{P}<.05$. 
is significant in the prediction of eating symptomatology (Ashby, Kottman, \& Schoen, 1998). However, this datum may be due to an inadequate assessment of the richness of the adaptive perfectionism. Future studies should consider perfectionism as a multidimensional construct and investigate separately the contribution of both functional and dysfunctional perfectionism in ED maintenance.

As well, body shame emerged as a predictor of the level of eating concerns. The severity of eating disorder symptomatology has been previously found to be associated to shame about the body (Doran \& Lewis, 2012). Further investigation might examine other forms of shame (specific and generalized). We consider the experience of shame as derived from a conflict linked to relationship with own bodies, which are the source of subjectivity and of the identity. Specifically, in our opinion, body shame acts as a mediator in the relationship between self-esteem and eating disorder risk. The sense of ineffectiveness that these individuals feel towards themselves could have been moved in their bodies through a defense mechanism. This would produce the bodily shame. From that perspective, eating disorders could be an attempt to modify the ashamed body, which has been considered responsible for individuals' ineffectiveness (Iannaccone, D'Olimpio, Cella, \& Cotrufo, 2016). The consistency across samples (AN, BN, BED) suggests that this mechanism is independent of body shape and weight.

Differently from previous research which failed to find low self-esteem as predictor of disordered eating behavior (Young, Clopton, \& Bleckley, 2004), our results revealed that this variable is a strong predictor of the level of eating concerns. This is in harmony with the idea that poor self-esteem is one of the prominent features strongly implicated in ED occurrence (Courtney, Gamboz, \& Johnson, 2008; Stein \& Corte, 2007; Polivy \& Herman, 2002).

Unexpectedly, perceived parental care/protectiveness

Table 3. Comparison among patients with different diagnoses in terms of the study variables.

\begin{tabular}{|c|c|c|c|c|c|}
\hline Variables & $\mathbf{H}_{(2)}$ & $\mathbf{P}$ & $\underset{(\mathbf{N}=\mathbf{3 9})}{\mathbf{A N}}$ & $\begin{array}{c}\text { erage sco } \\
\text { BN } \\
(\mathbf{N}=29)\end{array}$ & $\begin{array}{c}\text { BED } \\
(\mathrm{N}=12)\end{array}$ \\
\hline Age & 1.47 & .478 & 24.74 & 25.03 & 28.08 \\
\hline BMI & 17.08 & $.001^{\circ}$ & 17.94 & 20.24 & 27.52 \\
\hline ED duration (years) & .890 & .641 & 9 & 9.89 & 8.92 \\
\hline EDI-3 EDRC & 13.59 & $.001^{\#}$ & 51.89 & 69.86 & 56.66 \\
\hline PBI care & 2.33 & .311 & 38.79 & 36.03 & 32.33 \\
\hline $\mathrm{PBI}$ protectiveness & .88 & .643 & 32.87 & 31.62 & 34.75 \\
\hline RSES & 1.14 & .494 & 11.36 & 12.69 & 12.75 \\
\hline MPS total score* & 1.59 & .451 & 91.38 & 87.62 & 82.33 \\
\hline MPS organization & 2.34 & .310 & 24.13 & 22.45 & 21.50 \\
\hline ESS bodily shame & 3.12 & .210 & 12.79 & 13.62 & 14.08 \\
\hline
\end{tabular}

AN, anorexia nervosa; BN, bulimia nervosa; BED, binge eating disorder; BMI, body mass index; ED, eating disorder; EDI-3 EDRC, Eating Disorder Risk Composite from the Eating Disorders Inventory-3; PBI, Parental Bonding Instrument; RSES, Rosenberg Self Esteem Scale; MPS, Multidimensional Perfectionism Scale; ESS, Experience of Shame Scale. *MPS total score does not include organization; ${ }^{\circ} \mathrm{BED} \neq \mathrm{BN}=\mathrm{AN} ;{ }^{*} \mathrm{BED}=\mathrm{AN} \neq \mathrm{BN}$.

Table 4. Stepwise regression model and statistics for dependent variable.

\begin{tabular}{|c|c|c|c|c|c|c|c|c|}
\hline Model & $\mathbf{B}$ & Standard error & $\beta$ & $T$ & $\mathbf{P}$ & $R^{2}$ & Adjusted $R^{2}$ & $F$ \\
\hline 1. MPS total score* (Costant) & $\begin{array}{r}4.608 \\
.615\end{array}$ & $\begin{array}{r}9.884 \\
.109\end{array}$ & .538 & $\begin{array}{l}4.666 \\
5.643\end{array}$ & $\begin{array}{l}.642 \\
.000\end{array}$ & .290 & .281 & 31.838 \\
\hline 2. MPS total score* (Constant) & $\begin{array}{r}-19.382 \\
.491\end{array}$ & $\begin{array}{r}11.081 \\
.106\end{array}$ & .430 & $\begin{array}{r}-1.749 \\
4.651\end{array}$ & $\begin{array}{l}.084 \\
.000\end{array}$ & .403 & .387 & 25.961 \\
\hline ESS bodily shame & 2.629 & .689 & .353 & 3.815 & .000 & & & \\
\hline 3. MPS total score* (Constant) & $\begin{array}{r}9.059 \\
.389\end{array}$ & $\begin{array}{r}13.892 \\
.105\end{array}$ & .341 & $\begin{array}{r}.652 \\
3.696\end{array}$ & $\begin{array}{l}.516 \\
.000\end{array}$ & .471 & .450 & 22.537 \\
\hline ESS bodily shame & 2.173 & 669 & & 3.248 & .002 & & & \\
\hline RSES self-esteem & -1.106 & .354 & & -3.126 & .003 & & & \\
\hline
\end{tabular}

MPS, Multidimensional Perfectionism Scale; ESS, Experience of Shame Scale; RSES, Rosenberg Self Esteem Scale. *MPS total score does not include organization. 
did not emerge as predictors of the level of eating concerns. However, ED literature does not report analogous data. These dissimilarities may be due to the cultural differences. As well, it is possible that perceived parental bonding might participate in promoting the risk factors for eating pathology rather than in directly maintaining the disturbance. We suggest that the perception of parental hyper involvement may produce in subjects a feeling of ineffectiveness and impoverished self, which may be the root of eating psychopathologies. In our study curried out (Cella, Iannaccone, \& Cotrufo, 2014) parenting style characterized by over-protection and low levels of caring was associated with higher EDs vulnerability, and this association was mediated by personal factors such as self-.

The recognition of psychological variables and potential maintaining factors may support the choice of particular therapeutic strategies to improve the treatment of these patients and its outcomes. In the psychoanalytic literature on eating disorders frequent reference is made to an over-close mother-daughter relationship. An eating disorder can be understood, in this context, as a defensive means of attempting individuation and developing a separate identity from their mothers. Perhaps the major difficulty for therapeutic work is that for the these patients their disorder is a solution and not a problem. In our experience, psychodynamic psychotherapy is the treatment of choice for eating pathologies because it helps individuals to explore the underlying thoughts and emotions that have manifested in an eating disorder. These patients need help in their search for autonomy and identity. Particularly, the treatment of low self-esteem, maladaptive perfectionism and body shame may result in reductions in eating disorder symptomatology, and it could be helpful the parents of adolescent patients are seen in conjoint therapy by a colleague.

\section{Conclusions}

In conclusion, our findings stress the need to further investigate these factors as they might represent negative prognostic factors.

\section{Limitations}

Several aspects of the present study necessitate to be considered when interpreting these findings. First of all, we could not identify how individual variables operate together to produce risk or to maintain eating disturbances using statistical methods that consent causal interpretation of the data because of the small sample size that did not allow separation of patients with different diagnoses and use of structural equation model test. Research could need specific models of the perpetuating factors for each ED diagnosis. Moreover, study limitations include: i) the cross-sectional design that precludes a final conclusion with regard to directionality (these studies present a modest validity for confirmation of cause-effect relationships because, due to the cross-sectional nature of the design, we are unable to firmly comment upon causative links between perceived parenting, self-esteem, perfectionism, body shame and eating disorders, but we are only able to assess relationships between variables); ii) the exclusive use of self-report questionnaires that may have introduced falsified answers placing a limit on the data obtained; iii) the fact that patients had treatment and this may have influenced the course of the eating disturbance. Finally, the sample is very heterogeneous: adolescents, young adults and adults have different contexts and life goals. These limitations should be addressed in further studies.

\section{References}

APA (1994). Diagnostic and Statistical Manual of Mental Disorders ( $4^{\text {th }}$ ed.). Washington, DC: American Psychiatric Association.

APA (2000). Diagnostic and Statistical Manual of Mental Disorders ( $4^{\text {th }}$ ed., text rev.) Washington, DC: American Psychiatric Association.

Andrews, B., Qian, M., \& Valentine, J.D. (2002). Predicting depressive symptoms with a new measure of shame: the experience of shame scale. British Journal of Clinical Psychology, 41, 29-42.

Armstrong, D.M., \& Roth, J.G. (1989). Attachment and separation difficulties in eating disorders: a preliminary investigation. International Journal of Eating Disorders, 8, 141-155.

Ashby, J.S., Kottman, T., \& Schoen, E. (1998). Perfectionism and eating disorders reconsidered. Journal of Mental Health Counselling, 20, 261-271.

Bardone, A.M., Vohs, K.D., Abramson, L.Y., Heatherton, T.F., \& Joiner, Jr. T.E. (2000). The confluence of perfectionism, body dissatisfaction, and low self-esteem predicts bulimic symptoms: clinical implications. Behavior Therapy, 31, 265-280.

Bardone-Cone A.M., Wonderlich, S.A., Frost, R.O., Bulik, C.M., Mitchell, J.E., Uppala, S., Simonich, H. (2007). Perfectionism and eating disorders: current status and future directions. Clinical Psychology Review, 27, 384-405.

Bizeul, C., Sadowsky, N., \& Rigaud, D. (2001). The prognostic value of initial EDI scores in anorexia nervosa patients: a prospective follow-up study of 5-10 years. Eating disorder inventory. European Psychiatry, 16, 232-238.

Brown, L.S., \& Wright, J. (2001). Attachment theory in adolescence and its relevance to developmental psychopathology. Clinical Psychology \& Psychotherapy, 8, 15-32.

Burney, J., \& Irwin, H.J. (2000). Shame and guilt in women with eating-disorder symptomatology. Journal of Clinical Psychology, 56, 51-61.

Calam, R., \& Waller, G. (1998). Are eating and psychosocial characteristics in early teenage years useful predictors of eating characteristics in early adulthood? A 7-year longitudinal study. International Journal of Eating Disorders, 24, 351-362.

Calam, R., Waller G., Slade, P., \& Newton, T. (1990). Eating disorders and perceived relationships with parents. International Journal of Eating Disorders, 9, 479-485.

Canetti, L., Kanyas, K., Lerer, B., Latzer, Y., \& Bachar, E. (2008). Anorexia nervosa and parental bonding: the contribution of 
parent-grandparent relationships to eating disorder psychopathology. Journal of Clinical Psychology, 64, 703-716.

Cargill, B.R., Clark, M.M., Pera, V., Niaura, R.S., \& Abrams, D.B. (1999). Binge eating, body image, depression, and selfefficacy in an obese clinical population. Obesity Research, 7, 379-386.

Cella, S., Iannaccone, M., \& Cotrufo, P. (2014). How perceived parental bonding affects self-concept and drive for thinness: a community-based study. Eat Behaviors, 15, 110-115.

Cotrufo, P. (2005). Anoressia del sessuale femminile. Dal caos alla costituzione del limite. Milan: Franco Angeli.

Cotrufo, P., Gnisci, A., \& Caputo, I. (2005). Psychological characteristics of less severe forms of eating disorders: an epidemiological study among 259 female adolescents. Journal of Adolescence, 28, 147-154.

Courtney, E.A, Gamboz, J., \& Johnson, J.G. (2008). Problematic eating behaviors in adolescents with low self-esteem and elevated depressive symptoms. Eating Behaviors, 9, 408-414.

De Panfilis, C., Rabbaglio, P., Rossi, C., Zita, G., \& Maggini, C. (2003). Body image disturbance, parental bonding and alexithymia in patients with eating disorders. Psychopathology, 36, 239-246.

Doran, J., \& Lewis, C.A. (2012). Components of shame and eating disturbance among clinical and non-clinical populations. European Eating Disorders Review, 20, 265-270.

Egan, S.J., Wade, T.D., \& Shafran, R. (2011) Perfectionism as a transdiagnostic process: a clinical review. Clinical Psychological Review, 31, 203-212.

Fairburn, C.G. (1995). Overcoming binge eating. New York: Guilford Press.

Fassino, S., Amianto, F., Rocca, G., \& Daga, G.A. (2010). Parental bonding and eating psycho- pathology in bulimia nervosa: personality traits as possible mediators. Epidemiology and Psychiatric Sciences, 19, 214-222.

Frost, R.O., Marten, P., Lahart, C.M., \& Rosenblate, R. (1990). The dimensions of perfectionism. Cognitive Therapy Research, 14, 449-468.

Garner, D.M. (2004). Eating disorder inventory. Third edition (EDI-3). Lutz, FL: Psychological Assessment Resources.

Ghaderi, A. (2001). Eating disorders. Prevalence, incidence, and prospective risk factors for eating disorders among young adult women in the general population. Acta Universitatis Upsaliensis. Comprehensive Summaries of Uppsala Dissertations from the Faculty of Social Sciences; 99, 79 pp.

Grant, C.L., \& Fodor, I.G. (1986). Adolescent attitudes toward body image and anorexic behavior. Adolescence, 21, 269-281.

Greenberg, B.R., \& Harvey, P.D. (1986). The prediction of binge eating over time. Addictive Behavior, 11, 383-388.

Hayaki, J., Friedman, M.A., Brownell, K.D. (2001). Shame and severity of bulimic symptoms. Eating Behaviors, 3, 73-83.

Hilbert, A., Pike, K.M., Goldschmidt, A.B., Wilfley, D.E., Fairburn, C.G., Dohm, F.A. (2014). Risk factors across the eating disorders. Psychiatry Research, 15(220), 500-506.

Holland, L.A., Bodell, L.P., \& Keel, P.K. (2013). Psychological factors predict eating disorder onset and maintenance at 10year follow-up. Eur Eat Disord Rev; 21, 405-10.

Horesh, N., Sommerfeld, E., Wolf, M., Zubery, E., \& Zalsman, G. (2015). Father-daughter relationship and the severity of eating disorders. European Psychiatry, 30, 114-120.

Hudson, J.I., Hiripi, E., Pope, H.G. Jr., Kessler, R.C. (2007). The prevalence and correlates of eating disorders in the national comorbidity survey replication. Biological Psychiatry, 61, 348-358.
Iannaccone, M., D’Olimpio, F., Cella, S., \& Cotrufo, P. (2016). Self-esteem, body shame and eating disorder risk in obese and normal weight adolescents: a mediation model. Eat Behaviors, 2 (21), 80-83.

Jacobi, C., Paul, T., De Zwaan, M., Nutzinger, D.O., \& Dahme, B. (2004). Specificity of self-concept disturbances in eating disorders. International Journal of Eating Disorders, 35, 204-210.

Jankauskiene, R., \& Pajaujiene, S. (2012). Disordered eating attitudes and body shame among athletes, exercisers and sedentary female college students. Journal of Sports Medicine and Physical Fitness, 52, 92-101.

Jáuregui Lobera, I., Bolaños Ríos, P., \& Garrido Casals, O. (2011). Parenting styles and eating disorders. Journal of Psychiatry and Mental Health, 18, 728-735.

Joyce, F., Watson, H.J., Egan, S.J., \& Kane, R.T. (2012). Mediators between perfectionism and eating disorder psychopathology in a community sample. Eat Behaviors, 13, 361-365.

Kraemer, H.C., Stice, E., Kazdin, A., Offord, D., \& Kupfer, D. (2001). How do risk factors work together? Mediators, moderators, and independent, overlapping, and proxy risk factors. American Journal of Psychiatry, 158, 848-856.

La Mela, C., Maglietta, M., Caini, S. Casu, G.P, Lucarelli, S. Mori, S., Ruggiero, G.M. (2015). Perfectionism, weight and shape concerns, and low self-esteem: testing a model to predict bulimic symptoms. Eating Behaviors, 19, 155-158.

La Mela, C., Maglietta, M., Lucarelli, S., Mori, S., \& Sassaroli, S. (2013). Pretreatment outcome indicators in an eating disorder outpatient group: the effects of self-esteem, personality disorders and dissociation. Comprehensive Psychiatry, 54, 933-942.

Laporte, L., Marcoux, V., \& Guttman, H.A. (2001). Characteristics of families of women with restricting anorexia nervosa compared with families of normal probands. Encephale, 27, 109-119.

Loeb, K.L., Lock, J., Le Grange, D., \& Greif, R. (2012). Transdiagnostic theory and application of family-based treatment for youth with eating disorders. Cognitive Behavioral Practice, 19, 17-30.

Meyer, C., \& Gillings, K. (2004). Parental bonding and bulimic psychopathology: the mediating role of mistrust/abuse beliefs. International Journal of Eating Disorders, 35(2), 229-233.

Minuchin, S., Baker, L., Rosman, B.L., Liebman, R., Milman, L., \& Todd, T.C. (1975). A conceptual model of psychosomatic illness in children. Family organization and family therapy. Archives of General Psychiatry, 32, 1031-1038.

Murray, C., Waller, G., \& Legg, C. (2000). Family dysfunction and bulimic psychopathology: the mediating role of shame. International Journal of Eating Disorders, 28, 84-89.

Nilsson, K., Sundbom, E., \& Hägglöf, B. (2008). A longitudinal study of perfectionism in adolescent onset anorexia nervosarestricting type. European Eating Disorders Review, 16, 386-394.

Parker, G., Tupling, H., \& Brown, L.B. (1979). A parental bonding instrument. British Journal of Medical Psychology, 52, $1-10$.

Perry, J.A., Silvera, D.H., Neilands, T.B., Rosenvinge, J.H., \& Hanssen, T. (2008). A study of the relationship between parental bonding, self-concept and eating disturbances in Norwegian and American college populations. Eating Behaviors, 9, 13-24.

Polivy, J., \& Herman, C.P. (2002). Causes of eating disorders. Annual Review of Psychology, 53, 187-213. 
Rienecke, R.D., Accurso, E.C., Lock, J., \& Le Grange, D. (2016). Expressed Emotion, Family Functioning, and Treatment Outcome for Adolescents with Anorexia Nervosa. European Eating Disorders Review, 24, 43-51.

Rosenberg, M. (1965). Society and the adolescent self-image. Princeton, NJ: Princeton University Press.

Selvini Palazzoli, M. (1963). L'Anoressia mentale. Dalla terapia individuale alla terapia familiare. Milano: Feltrinelli.

Shea, M.E., \& Pritchard, M.E. (2007). Is self-esteem the primary predictor of disordered eating? Personal and Individual Differences, 42, 1527-1537.

Sjöberg, R.L., Nilsson, K.W., \& Leppert, J. (2005). Obesity, shame, and depression in school-aged children: a population-based study. Pediatrics, 116, e389-e392.

Stein, K.F., \& Corte, C. (2007). Identity Impairment and the eating disorders: content and organization of the self-concept in women with anorexia nervosa and bulimia nervosa. European Eating Disorders Review, 15, 58-69.

Stice, E., Marti, C.N., \& Durant, S. (2011). Risk factors for onset of eating disorders: evidence of multiple risk pathways from an 8-year prospective study. Behavior Research Therapy, 49, 622-7.

Sutandar-Pinnock, K., Blak Woodside, D., Carter, J.C., Olmsted, M.P., \& Kaplan, A.S. (2012). Perfectionism in anorexia nervosa: a 6-24-month follow-up study. International Journal of Eating Disorders, 33, 225-229.

Swanson, H., Power, K., Collin, P., Deas, S., Paterson, G., Grierson, D., ..., \& Taylor L. (2010). The relationship between parental bonding, social problem solving and eating pathology in an anorexic inpatient sample. European Eating Disorders Review, 18, 22-32.
Teixeira, D., Pereira, A.T., Marques, M.V., Saraiva, J.M., \& de Macedo, A.F. (2016). Eating behaviors, body image, perfectionism, and self-esteem in a sample of Portuguese girls. Review of Brasilian Psychiatry, 38 (2), 135-140.

Tetley, A., Moghaddam, N.G., Dawson, D.L., \& Rennoldson, M. (2014). Parental bonding and eating disorders: a systematic review. Eating Behaviors, 15(1), 49-59.

Troop, N.A., \& Redshaw, C. (2012). General shame and bodily shame in eating disorders: a 2.5-year longitudinal study. European Eating Disorders Review, 20, 373-378.

VanVoorhis, C., \& Morgan, B. (2001). Statistical rules of thumb: what we don't want to forget about sample sizes. Psychology Journal, 6, 139-141.

Wade, T.D., Wilksch, S.M., Paxton, S.J., Byrne, S.M., \& Austin, S.B. (2015). How perfectionism and ineffectiveness influence growth of eating disorder risk in young adolescent girls. Behavioral Research Therapy, 66, 56-63.

Watson, H.J., Steele, A.L., Bergin, J.L., Fursland, A., \& Wade, T.D. (2011). Bulimic symptomatology: The role of adaptive perfectionism, shape and weight concern, and self-esteem. Behavioral Research Therapy, 49, 565-572.

Wood, A., Waller, G., \& Gowers, S. (1994). Predictors of eating psychopathology in adolescent girls. Eating Disorders Review, 2, 6-13.

Yamaguchi, N., Kobayashi, J., Tachikawa, H., Sato S., Hori, M., Suzuki, T., Shiraishi, H. (2000). Parental representation in eating disorder patients with suicide. Journal of Psychosomatic Research, 49, 131-6.

Young, E.A., Clopton, J.R., \& Bleckley, M.K. (2004). Perfectionism, low self-esteem, and family factors as predictors of bulimic behavior. Eating Behaviors, 5, 273-283. 